\title{
Proteomics-Based Identification of the Molecular Signatures of Liver Tissues from Aged Rats following Eight Weeks of Medium-Intensity Exercise
}

\author{
Fanghui Li, ${ }^{1,2}$ Tao Li, $^{3}$ and Yanying Liu ${ }^{1}$ \\ ${ }^{1}$ School of Physical Education and Health, Zhaoqing University, Zhaoqing 526016, China \\ ${ }^{2}$ Exercise Health and Technology Centre, Shanghai Jiao Tong University, Shanghai 200240, China \\ ${ }^{3}$ Laboratory of Laser Sports Medicine, South China Normal University, Guangzhou 510006, China \\ Correspondence should be addressed to Fanghui Li; fanghuili2007@163.com
}

Received 4 June 2016; Revised 5 September 2016; Accepted 28 November 2016

Academic Editor: Ravirajsinh Jadeja

Copyright ( 2016 Fanghui Li et al. This is an open access article distributed under the Creative Commons Attribution License, which permits unrestricted use, distribution, and reproduction in any medium, provided the original work is properly cited.

\begin{abstract}
Physical activity has emerged as a powerful intervention that promotes healthy aging by maintaining the functional capacity of critical organ systems. Here, by combining functional and proteomics analyses, we examined how hepatic phenotypes might respond to exercise treatment in aged rats. 16 male aged (20 months old) SD rats were divided into exercise and parallel control groups at random; the exercise group had 8 weeks of treadmill training with medium intensity. Whole protein samples of the liver were extracted from both groups and separated by two-dimensional gel electrophoresis. Alternatively objective protein spots with $>2$-fold difference in expression were selected for enzymological extraction and MS/MS identification. Results show increased activity of the manganese superoxide dismutase and elevated glutathione levels in the livers of exercise-treated animals, but malondialdehyde contents obviously decreased in the liver of the exercise group. Proteomics-based identification of differentially expressed proteins provided an integrated view of the metabolic adaptations occurring in the liver proteome during exercise, which significantly altered the expression of several proteins involved in key liver metabolic pathways including mitochondrial sulfur, glycolysis, methionine, and protein metabolism. These findings indicate that exercise may be beneficial to aged rats through modulation of hepatic protein expression profiles.
\end{abstract}

\section{Introduction}

Sedentary habits are associated with low levels of physical fitness and a high risk of mortality [1], whereas physical activity has emerged as a powerful intervention that promotes successful aging by maintaining general physical fitness [2]. However, the physiological mechanisms underlying physical activity-induced physical fitness are only partly understood.

Exercise-induced oxygen consumption increases associated with energy metabolism adaptation might be involved in physical fitness [3]. The first direct evidence of this was provided by Davies et al. [4] through the demonstration that high-intensity exercise enhances reactive oxygen species (ROS) production. Although high concentrations of ROS can damage proteins, lipids, and nucleic acids, further evidence suggests that exercise promotes the formation of ROS, which participate in redox regulation. In particular, moderate concentrations of ROS function as regulatory mediators to reestablish "redox homeostasis" in signaling processes $[5,6]$. In this context, exercise-induced ROS may be involved in the establishment of physical fitness [7].

Although the potential effects of muscular ROS have been explored in depth, the role and related mechanisms of ROS in the hepatic adaptation induced by exercise have not been extensively studied [8]. Several recent findings have resulted in physical activity being prescribed as part of the overall strategy (or therapy) to reduce the risk of senescence-associated liver metabolic syndrome. The potential mechanisms of this protective role might involve the enhancement of hepatic insulin sensitivity and the activities of antioxidant enzymes, the attenuation of lipid accumulation in the liver, and subsequent prevention of hyperglycemia, 
hypercholesterolemia, and liver diseases (such as nonalcoholic steatohepatitis or cirrhosis) [9]. In addition, ROS are direct triggers of liver insulin resistance [10] and inflammation [11]. In contrast, however, evidence from rats indicates that regular exercise can attenuate hepatic oxidative stress [12]. Nonetheless, further research is needed to evaluate the detailed mechanism of ROS in the hepatic adaptation induced by exercise.

Given the multitude of changes that occur in each organ during exercise, genetic and epigenetic studies might be able to elucidate the biology underlying the individual response to exercise [13]. 2D gel tandem mass spectrometrybased proteomic methods are valuable tools for quantifying differences in protein abundance between different physical conditions or treatments [14]. Current proteomic methods allow the identification of several thousand proteins from microgram quantities of proteins in skeletal muscle, cardiomyocytes [15], adipose tissue [16], and liver [7, 17, 18]. In addition, proteomics analysis has previously been performed by several groups to determine how liver proteome profiles differ between exercise-trained and untrained individuals [18], which might provide information that could be of benefit in combating the effects of postmenopause or of nonalcoholic fatty liver disease-related loss of liver function including metabolic syndrome by promoting redox homeostasis. However, insight into the adaptive response of liver tissue proteome signatures during aging under a variety of regular exercise challenges is still required [19]. In the current study, we focused our attention specifically on the putative phenotypic/metabolic adaptations in the liver of aged rats that were induced by eight weeks of medium-intensity exercise.

\section{Material and Methods}

2.1. Subjects. In total, 16 male adult Sprague-Dawley (SD) rats (Rattus norvegicus, Guangdong Medical Laboratory Animal Center (GDMLAC), Guangdong, China) with similar body weights (range of 340-260 g), aged 18 months at the beginning of the training period, were randomly distributed into two groups: treadmill exercise $(n=8)$ (EXE) and sedentary control $(n=8)(\mathrm{CON})$. The animals were fed standard laboratory chow and water ad libitum while housed (3-5 per cage) in a temperature-controlled room $\left(22^{\circ} \mathrm{C}\right)$ with $12 \mathrm{~h}$ dark/light cycles. All animal protocols were approved by the local Experimental Animal Use Committee.

2.2. Endurance Training. The animal exercise protocol was as follows: the training intensity was progressively increased. For the first 4 weeks, the speed of the treadmill and duration of the training sessions were gradually increased from a speed of $10 \mathrm{~m} / \mathrm{min}$ for $10 \mathrm{~min}$ to a running speed of $15 \mathrm{~m} / \mathrm{min}$ for $60 \mathrm{~min}$ by the end of week 4 . For the next 4 weeks, a $5 \mathrm{~min}$ warm-up session at a speed of $10 \mathrm{~m} / \mathrm{min}$ was followed by the $60 \mathrm{~min}$ training session at a speed of $15 \mathrm{~m} / \mathrm{min}$ [20]. This training protocol was developed based on previous experience training in rodents [21], but minor modifications were applied according to another training protocol [22]. The intensity and duration were chosen based on previous reports from the groups of Song and Bejma in which a similar speed of $15 \mathrm{~m} / \mathrm{min}$ and a similar parameter of $60 \mathrm{~min} /$ bout were applied, which resulted in a series of positive changes such as increased activity of antioxidant enzymes in the aging liver $[21,23]$. The 8 -week exercise program of treadmill running at $0^{\circ}$ incline was chosen based on previous reports from the Siu group [22]. Training animals and control animals were sacrificed $6 \mathrm{~h}$ after the last training session. The liver tissues were quickly removed and frozen immediately in liquid nitrogen and stored at $-80^{\circ} \mathrm{C}$ until further analysis.

2.3. Assay of Malondialdehyde (MDA) and Glutathione (GSH) Contents as well as Superoxide Dismutase (SOD) Activity in the Livers of Old Rats. For biochemical analyses of in vivo MDA, GSH, and SOD activity, $20 \mathrm{mg}$ of liver tissue was homogenized on ice in phosphate-buffered saline and centrifuged for $10 \mathrm{~min}$ at $12,000 \times \mathrm{g}$ at $4^{\circ} \mathrm{C}$. The supernatant was collected and analyzed. MDA level, GSH content, and SOD activity were determined using commercial assay kits produced by Nanjing Jiancheng Bioengineering Institute, China. Protein concentrations were determined using a BCA protein assay kit (Nanjing Jiancheng Biochemistry Co.) as described by the manufacturer.

\subsection{Proteomics Analysis}

2.4.1. Sample Preparation for Two-Dimensional Gel Electrophoresis (2DGE). We selected 8 "EXE" and 8 "CON" rats for proteomics analysis. From these animals, $50 \mathrm{mg}$ of liver was homogenized in $500 \mu \mathrm{L}$ of sample buffer [ $(7 \mathrm{M}$ urea, $2 \mathrm{M}$ thiourea, $4 \%(\mathrm{w} / \mathrm{v})$ dimethyl[3 propyl] azaniumyl propane1-sulfonate (CHAPS), 1\% (v/v) immobilized $\mathrm{pH}$ gradient (IPG) buffer pH 3-10 NL) (Amersham Biosciences, Piscataway, NJ, USA), $40 \mathrm{mM}$ dithiothreitol (DTT), and Protease Inhibitor Cocktail Complete (Roche, Mannheim, Germany)] and allowed to stand at room temperature for $1 \mathrm{~h}$, after which the homogenate was then centrifuged at $40,000 \times \mathrm{g}$ for $60 \mathrm{~min}$ at $4^{\circ} \mathrm{C}$. Subsequently, the supernatant was removed and the protein concentration was measured using the Bradford protein assay. Homogenates were stored at $-70^{\circ} \mathrm{C}$ for later use. 2-DE was performed using a $24 \mathrm{~cm}$ (nonlinear, $\mathrm{pH} 3.0-$ 10.0) IPG gel strip, according to Sun et al. [24]. Spot detection, gel matching, and interclass analysis were performed using PDQuest 8.0 software (Amersham Biosciences, USA) [24].

2.4.2. In-Gel Tryptic Digestion and Matrix-Assisted Laser Desorption/Ionization-Time of Flight Mass Spectrometry (MALDI-TOF MS/MS). In-gel digestion and protein identification were performed as described by Perkins et al. [25]. Candidate spots were excised from the stained gel, destained with $0.1 \mathrm{M}$ ammonium bicarbonate in $50 \%$ acetonitrile (Sigma-Aldrich, St. Louis, MO, USA), and dried using a SpeedVac SC110 (Savant Instruments, Holbrook, NY, USA). The gels were then rehydrated and incubated in trypsin solution (Promega, Madison, WI, USA) overnight at $37^{\circ} \mathrm{C}$, and the peptide mixtures were then analyzed using MALDI-TOF MS/MS (Applied Biosystems, Foster City, CA, USA) [25]. 


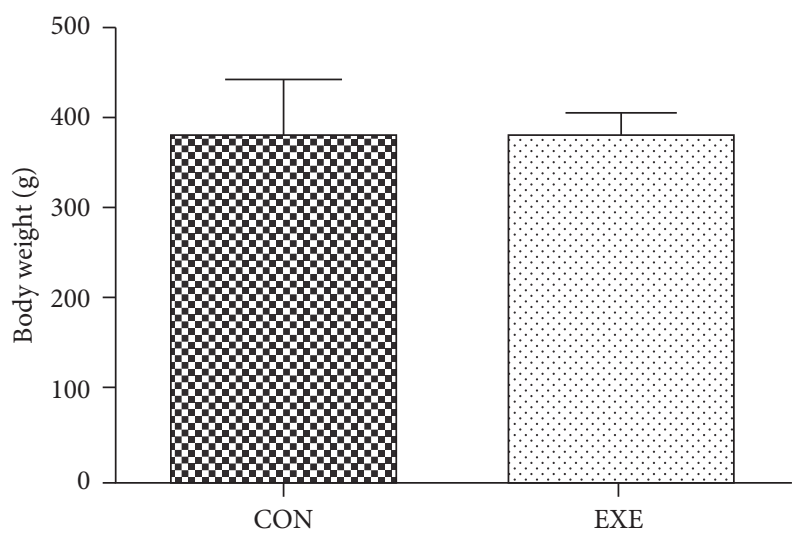

(a)

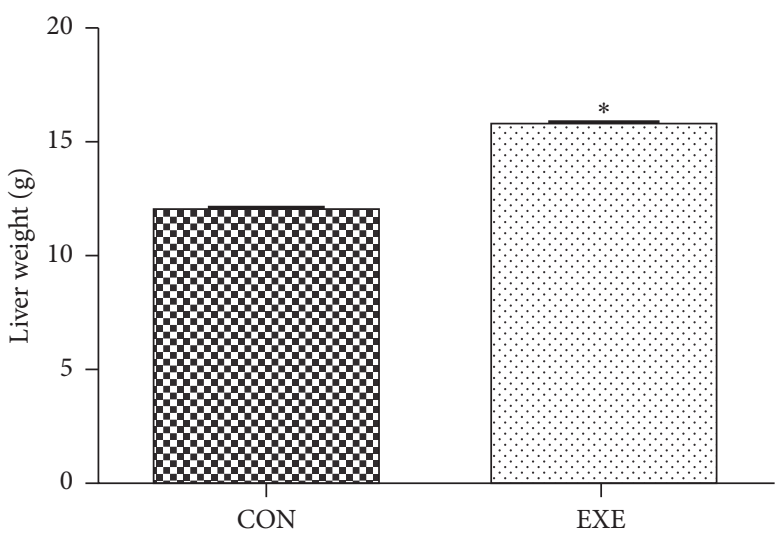

(b)

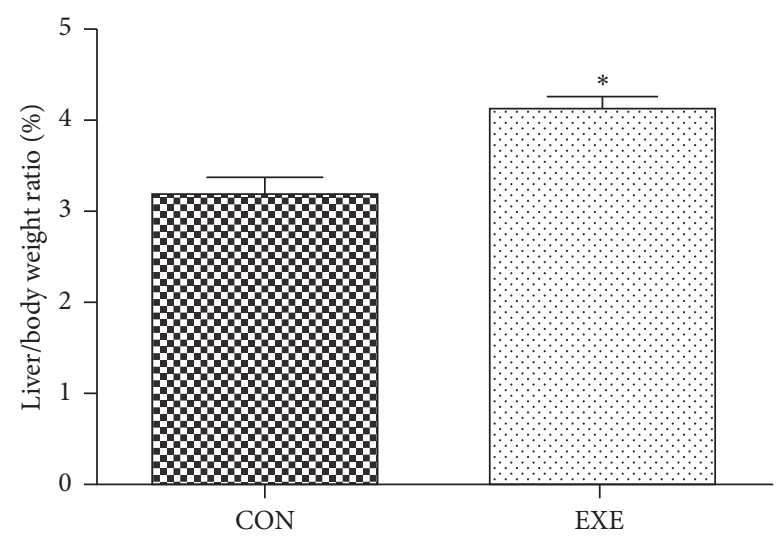

(c)

Figure 1: Body weight and ratio of liver weight to whole body weight. Body weight (a), liver weight (b), and liver/body weight (c). Values represent the mean $\pm \mathrm{SEM} ; n=8$ per group. ${ }^{*} P<0.05$ versus the control group.

2.4.3. Database Searching. Proteins were identified by peptide mass fingerprinting with the search engine programs MASCOT [25]. The criteria for positive identification of proteins were according to Perkins et al. [25] and were set as follows: (i) at least four matching peptide masses, (ii) $50 \mathrm{ppm}$ or better mass accuracy, and (iii) matching of the molecular weights $(\mathrm{Mr})$ and isoelectric points $(\mathrm{pI})$ of the identified proteins to the estimated values obtained from image analysis.

2.5. Statistical Analysis. Statistical analysis was performed using predictive analytics software statistics 16.0 (SPSS Inc., Chicago, IL, USA). Comparisons across the experimental groups were performed using Student's $t$-test. For the analyses, the significance level was set at 5\% $(P<0.05)$. Data are presented in the figures as the mean \pm standard error of the mean (SEM).

\section{Results}

3.1. Liver Weights and Liver Weight/Body Weight Ratios between Sedentary and Exercised Aged Rats. The ratio of the weight of the liver to the whole animal body weight was determined. As shown in Figure 1, no difference in body weight was observed between exercised (EXE) and sedentary control (CON) groups. However, liver weight and liver weight/body weight ratio were higher for the livers of EXE animals than for those of the CON group $(P<0.05)$.

3.2. Effects of Treadmill Training on the Oxidative Status of the Livers of Aged Rats. Changes in the levels of hepatic MDA and GSH contents as well as in MnSOD activity in response to 8-week moderate-intensity treadmill training were analyzed. As shown in Figure 2, after 8 weeks of treadmill training, MnSOD activity, hepatic GSH level, and $\mathrm{GSH}$ /oxidized glutathione (GSSH) ratio in the EXE group were significantly higher in comparison to the CON group $(P<0.05$, Figure 2$)$, whereas the hepatic MDA and GSSH levels were decreased $(P<0.01$, Figure 2$)$.

3.3. Proteomics Comparison of Hepatic Expression Profiles between Sedentary and Exercised Aged Rats. The hepatic protein profiles are shown in Figure 3. Following gel image analysis, differentially expressed spots were selected and identified using MALDI-TOF MS when the normalized spot intensities showed differences of at least 2 -fold between the groups. The 


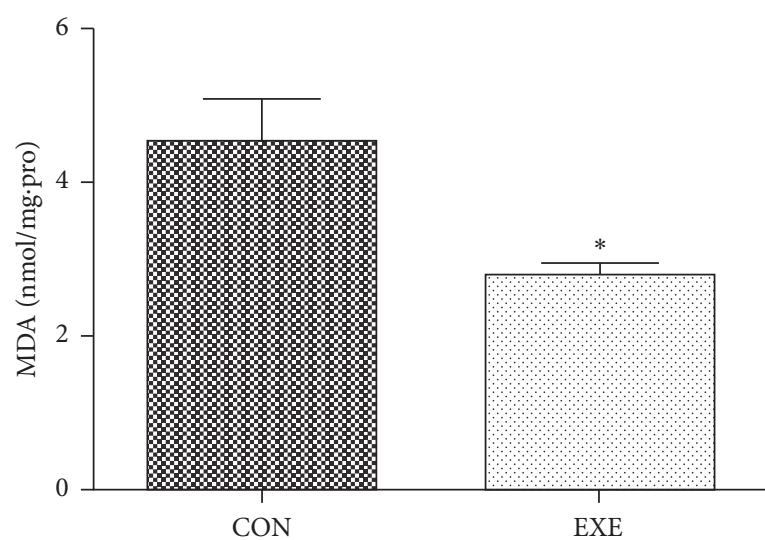

(a)

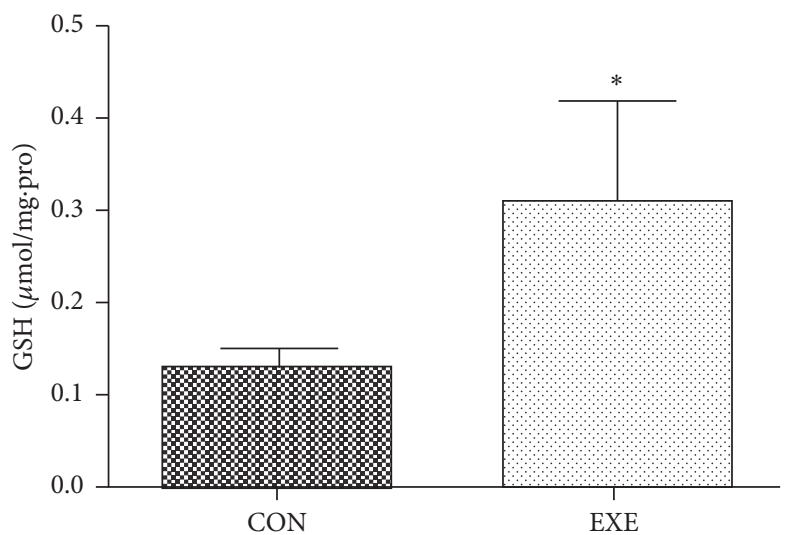

(c)

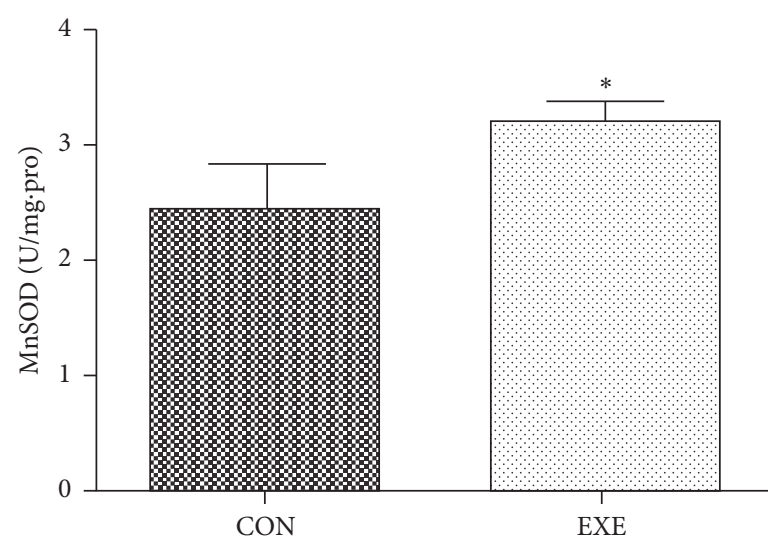

(b)

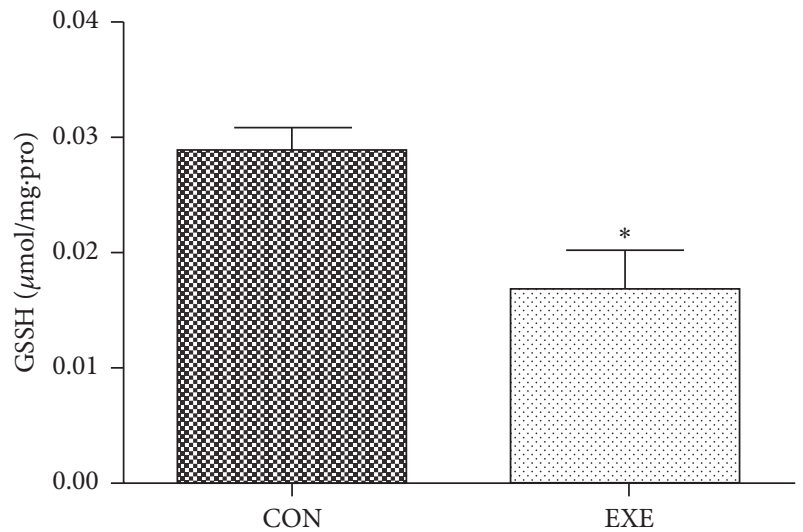

(d)

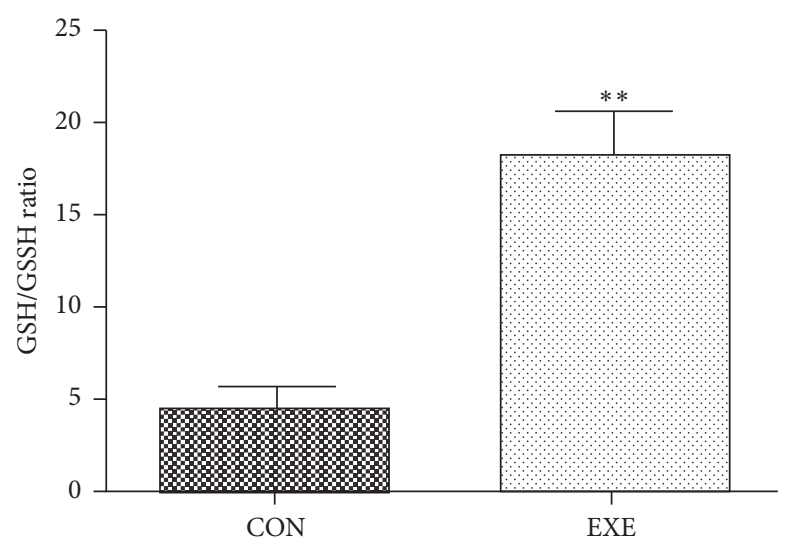

(e)

FIgURE 2: Antioxidant enzyme activity and MDA in the livers of control (CON) and exercised (EXE) groups. MDA (a), MnSOD (b), GSH (c), GSSH (d), and GSH/GSSH ratio (e). Values represent the mean \pm SEM; $n=8$ per group. ${ }^{*} P<0.05$ versus the control group, ${ }^{* *} P<0.01$ versus the control group.

12 proteins identified as differentially expressed are listed in Table 1. The experimental ratios of the $\mathrm{Mr}$ and pIs matched those of the theoretical data, suggesting that the identification of proteins by our proteomic method was reliable.

\section{Discussion}

The liver is the primary organ required for processing of nutrients, hormones, and drugs; therefore, to evaluate exercise-dependent antiaging effects and adaptive alterations in the proteome of the livers of aged rats after 8 weeks of moderate-intensity training exercise, total liver tissue extracts from sedentary aged rats (22 months, control) and aged rats that were provided exercise training were resolved by 2DGE. 2DGE with medium-range IPGs ( $\mathrm{pH}$ 3-10) revealed 3839 protein spots in the liver that were matched among all rats. Among these protein spots, 35 were found to be differentially expressed in the liver between sedentary and exercised rats, of 


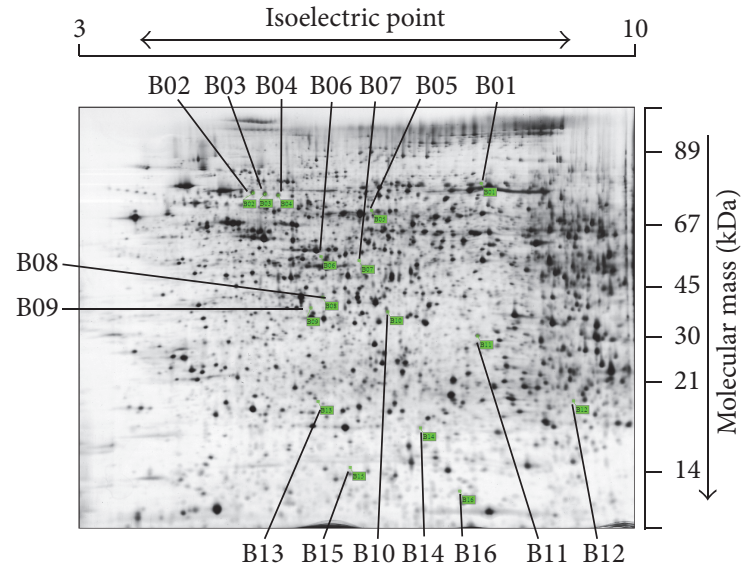

(a)

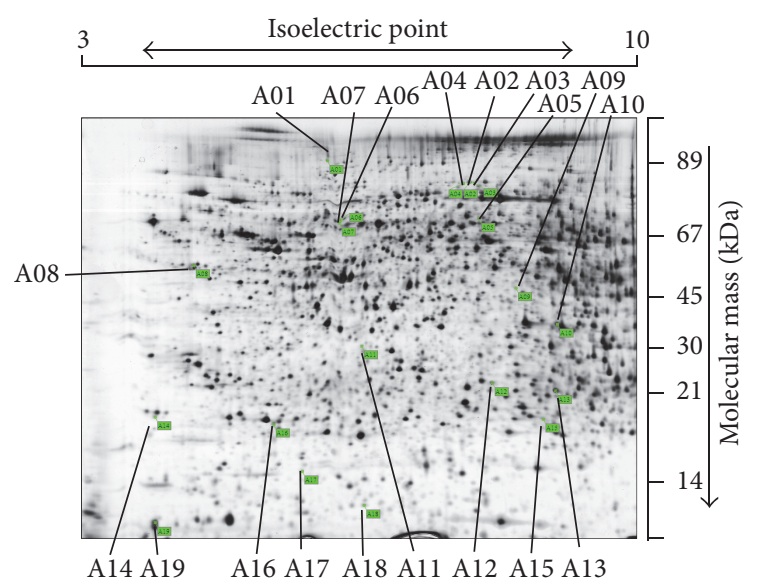

(b)

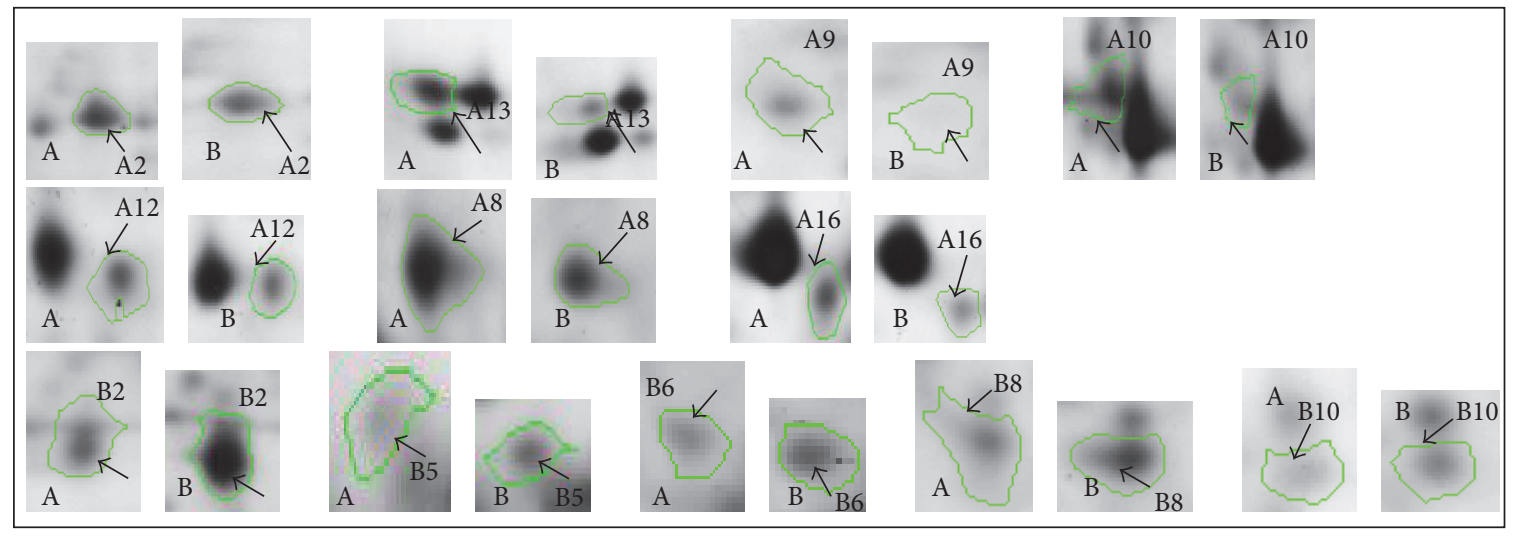

(c)

FIGURE 3: Two-dimensional gel electrophoresis (2DGE) image analysis of the liver of aged rats following exercise. (a) Sedentary control (CON) group. (b) Exercise training (EXE) group. Statistically significant spots are indicated by arrows in each gel; numbers 1-12 indicate the up- or downregulated proteins in the exercise group (c).

which 12 were identified by MALDI-TOF MS/MS (Figure 3). From these proteins, we elucidated that age-related hepatic proteome changes were effectively reversed through exercise, which might be beneficial to combat health conditions related to age-related abnormal liver morphology through regulation of mitochondrial energy metabolism, proteolytic systems, detoxification, and quality control of cellular and cytoskeletal proteins.

Among the identified proteins, FAS activity is believed to be a determinant of the maximal capacity of the liver to synthesize fatty acids by de novo lipogenesis. Advanced age has been associated with upregulation of FAS expression and enzymatic activity, which in turn has been found to be an underlying contributor to many age-related conditions including hepatic steatosis [26] and necroinflammation [27]. Aging is also associated with variable degrees of fibrosis in the liver. Our results showed that moderate-intensity training exercise decreased the abundance of FAS protein, a marker of hepatic fibrosis.

SAFB1 has been shown to be important in numerous cellular processes including cell growth, stress response, and apoptosis [28]. Studies performed by the Gelman group have shown that SAFB1 can repress the transcriptional activity of various other nuclear receptors including estrogen receptor [29], heat shock factor 1 [30], and p53 [31]. Additional studies identified that SAFB1 regulates the expression of xanthine oxidoreductase (XOR) [32], peroxisome proliferatoractivator receptor (PPAR) gamma [33], and sterol regulatory element-binding protein- (SREBP-) 1c [33]. SREBP$1 c$ and PPAR gamma are transcription factors that control the expression of hepatic genes involved in fatty acid and triglyceride synthesis during overnutrition to facilitate the conversion of glucose to fatty acids and triglycerides for the storage of the excess energy [34]. Additionally, in this context, it should be noted that SAFB1 was found to be downregulated by exercise, which is probably related to a decrease in lipogenesis as suggested by decreased abundance of the FAS protein. Furthermore, Lee et al. [35] showed that SAFB1 is also involved in the later stages of apoptosis, in which it is possibly associated with endonuclease-mediated DNA cleavage. These data clearly suggest that downregulation of SAFBl in the liver might play an important role in age-related fatty acid metabolism, apoptosis, and oxidative stress, which are the primary causes of fatty liver disease. 
TABLE 1: Proteins differentially expressed in aged rat livers after exercise training, determined using MALDI-TOF MS/MS.

\begin{tabular}{|c|c|c|c|c|c|c|}
\hline $\begin{array}{l}\text { Spot } \\
\text { number }\end{array}$ & $\begin{array}{c}\text { GI } \\
\text { number }\end{array}$ & $\begin{array}{l}\text { Sequence } \\
\text { Cov. }(\%)\end{array}$ & $\begin{array}{c}\text { Measured Mr } \\
(\mathrm{kDa}) / \mathrm{pI}^{\mathrm{a}}\end{array}$ & $\begin{array}{l}\text { MOWSE } \\
\text { score }^{b}\end{array}$ & Protein identification & $\begin{array}{c}\text { Fold } \\
\text { change }\end{array}$ \\
\hline A2 & 8394158 & 7 & $275101 / 5.96$ & 197 & Fatty acid synthase (FAS) & -2.08 \\
\hline A8 & 132573 & 21 & $51653 / 4.67$ & 77 & $\begin{array}{l}\text { Ribonuclease/angiogenin inhibitor } 1 \\
\text { (RNASE1) }\end{array}$ & -2.04 \\
\hline A9 & 158186651 & 20 & $47440 / 6.16$ & 347 & $\alpha$-Enolase (ENO1) & -2.30 \\
\hline $\mathrm{A} 10$ & 19924087 & 22 & $37517 / 6.67$ & 76 & $\begin{array}{l}\text { Hydroxyprostaglandin dehydrogenase } \\
\text { (11 } \beta \text {-HSD1) }\end{array}$ & -2.64 \\
\hline A12 & 734703982 & 10 & $112398 / 5.99$ & 52 & Scaffold attachment factor B (SAFB) & -3.13 \\
\hline A13 & 149056650 & 38 & $28234 / 6.78$ & 81 & $\begin{array}{l}\text { Ethylmalonic encephalopathy protein } 1 \\
\text { (ETHE1) }\end{array}$ & -2.20 \\
\hline A16 & 54019419 & 28 & $25502 / 4.85$ & 215 & Proteasome subunit beta type-6 (PSMB6) & +2.85 \\
\hline B2 & 80861401 & 10 & $48828 / 6.08$ & 204 & T-kininogen & +2.32 \\
\hline B5 & 730311 & 18 & $61650 / 6.30$ & 149 & Glucose phosphomutase (PGM) & +2.60 \\
\hline B6 & 205057 & 39 & $48828 / 5.83$ & 204 & Keratin $8(\mathrm{~K} 8)$ & +2.94 \\
\hline B8 & 77157805 & 16 & $44240 / 5.61$ & 139 & $\begin{array}{l}\text { S-Adenosylmethionine synthetase isoform } \\
\text { type-1 (SAMs) }\end{array}$ & +2.55 \\
\hline $\mathrm{B} 10$ & 59808182 & 12 & $39052 / 6.10$ & 146 & Haptoglobin (HP) & +2.14 \\
\hline
\end{tabular}

${ }^{a}$ Theoretical $\mathrm{pI}$ and $\mathrm{Mr}$ derived from NCBInr and Swiss Prot/TrEML databases.

${ }^{\mathrm{b}}$ Score is $-10 \times \log (P)$, where $P$ is the probability that the observed match is a random event, based on the NCBInr database using the MASCOT searching program as MALDI-TOF MS/MS data (http://www.matrixscience.com/).

In a previous study, perturbations in the energy metabolism of aged livers were indicated by the downregulation of several glycolytic enzymes [36]. Moreover, Rothwell and Sayce found that enhancement of glycolysis via PGM can protect cells from oxidative stress, thus preventing senescence [37]. The classical function of PGM is to link glycolysis and glycogen metabolism by interconverting glucose-1-phosphate and glucose-6-phosphate. PGM has been shown to be expressed ubiquitously; however, high levels of expression are observed in the heart, skeletal muscle, kidney, liver, and lungs [37]. The activity of PGM is under hormonal control and may play a physiological role in glucose metabolism and physical activity [38]. Notably, proteomics analysis has revealed decreased expression of PGM in elderly women [39]. Recent evidence indicates that downregulation of PGM is associated with hepatocyte failure in cirrhotic hepatocytes, especially at the late stages of cirrhosis [40]. In addition, Preisler et al. [41] implied that the liver might be affected by PGM deficiency and that reduced liver glucose levels might contribute to the low blood glucose levels observed during exercise in this condition. In this regard, polymorphism in PGM has been reported to be useful as a genetic biomarker for alcoholic cirrhosis [42], ischemic heart disease [43], and obesity disorders [44, 45]. The results of the current study show that training exercise increased the protein content of PGM in the livers of old rats, which likely contributed to the improved glycolytic metabolism of these animals, despite their advanced cirrhosis.

Notably, $\alpha$-enolasel (ENO1), a glycolytic enzyme that catalyzes the conversion of 2-phosphoglycerate to phosphoenolpyruvate, was found to be downregulated in the liver of old rats after moderate-intensity training exercise, as shown in Figure 3. ENO1 is highly expressed in liver tissue and in the cytoplasm of hyperplastic bile ducts [46]. In addition to its key contribution in the regulation of glycolysis and the generation of ATP, ENO1 also plays a crucial role in growth control, hypoxia tolerance, and allergic responses [47]. Notably, a previous study had used an immunoproteomics approach to identify and characterize ENO1 as an autoantigen in liver fibrosis [48]. Although it is unclear whether ENO1 plays an active role during the formation of liver fibrosis, it has also been reported that ENO1 is transcriptionally regulated by the c-Jun NH2-terminal kinase (JNK) signaling pathway, which is frequently activated in liver fibrosis [49]. Furthermore, ENO1 might act as an oxidative stress-related mediator to modulate the tissue and cellular events responsible for the progression of liver fibrosis [50]. Our results show a decreased protein content of ENO1 at 8 weeks after moderateintensity training exercise in aged rats, in parallel with an increase in MnSOD activity and in the hepatic GSH level and GSH/GSSH ratio (Figure 2), which likely contributes to improved liver fibrosis and liver function. However, whether or not the improvement of liver function mediated by training exercise is associated with modulation of ENO1 in the livers of aged rats requires further study.

A previous study demonstrated that $11 \beta$-HSD1 catalyzed the intracellular regeneration of active glucocorticoids, promoting insulin resistance in the liver [51], and elevated mRNA levels for $11 \beta$-HSD1 in the liver were associated with aging [52]. Fatty liver occurs in mice that overexpress $11 \beta$ HSD1 as a result of increases in gluconeogenesis, fatty acid synthesis, and plasma insulin levels [53]. Thus, the agedependent increase in the mRNA level of $11 \beta$-HSD1 is likely to induce insulin secretion and cause hyperinsulinemia. Recent evidence indicates that exercise protects against the elevations in glucocorticoids associated with the development of insulin 
resistance by decreased adrenal sensitivity to the $11 \beta-\mathrm{HSD} 1$ content in the livers of diabetic fatty rats [54]. Consistent with these findings, aged rats that exhibited higher hippocampal corticosterone levels also showed increased $11 \beta$-HSD1 protein expression as well as increased levels of the enzyme that catalyzes glucocorticoid formation and greater hippocampal glucocorticoid receptor (GR) activation, whereas exercise as a therapeutic intervention significantly reduced total hippocampal GR and 11 $\beta$-HSD1 expression in these animals [55]. Similarly, the results of the current study show that $11 \beta$-HSD1 protein expression significantly decreased after 8 weeks of aerobic exercise; as discussed above, this decrease in $11 \beta$ HSD1 expression is believed to play an important role in mitigating age-related fatty acid metabolism, gluconeogenesis, and hyperinsulinemia, which is a main cause of insulin resistance in the liver.

The liver is an important organ for $\mathrm{H}_{2} \mathrm{~S}$ production and clearance, and hepatic $\mathrm{H}_{2} \mathrm{~S}$ metabolism affects multiple metabolic processes. In contrast, malfunction of hepatic $\mathrm{H}_{2} \mathrm{~S}$ metabolism might be involved in the pathogenesis of many liver diseases such as hepatic fibrosis and cirrhosis [56]. The mitochondrial dioxygenase gene ETHE1 encodes a mitochondrial enzyme involved in sulfide detoxification, which uses molecular $\mathrm{O}_{2}$ and water to oxidize the mobile persulfide from quinone oxidoreductase to form sulfite, which in turn is involved in sulfur metabolism and takes part in the pathway in which $\mathrm{H}_{2} \mathrm{~S}$ is oxidized to thiosulfate in three steps [57]. Although the basal endogenous concentration of $\mathrm{H}_{2} \mathrm{~S}$ has been found to have a hepatoprotective effect [58], inhibition of this pathway prevents binding of $\mathrm{H}_{2} \mathrm{~S}$ to quinone oxidoreductase and enables the accumulation of $\mathrm{H}_{2} \mathrm{~S}$ and thiosulfate, which induces oxidative stress and hepatotoxicity (e.g., by inhibiting the respiratory chain and decreasing cellular $\mathrm{NAD}^{+} / \mathrm{NADH}$ ) in the liver during aging [59]. Thus, the decreased levels of ETHE1 in the rats fed a high-fat diet might allow the occurrence of higher concentrations of $\mathrm{H}_{2} \mathrm{~S}$, which might mitigate some of the risks of high blood pressure and oxidative stress associated with obesity and aging [60]. However, ETHE1 is also an antiapoptotic protein that increases the deacetylase activity of p53 in association with histone deacetylase 1, leading to the suppression of apoptosis [61].

S-Adenosylmethionine (SAMe) is an important methyl donor in various methyltransferase reactions that occur in many lipid metabolic pathways. SAMs catalyzes the synthesis of SAMe from methionine in the presence of ATP, which is the major pathway in mammals for the metabolism of methionine [62]. Previous studies have indicated that a marked loss of SAMs was accompanied by a reduction of the concentration of SAMe in cirrhosis [62] and that treatment with SAMe increased hepatic GSH levels and increased survival in patients with less advanced alcoholic liver cirrhosis [63]. Our data therefore support that SAMs upregulates SAMe via exercise, which in turn increases the levels of hepatic GSH (Figure 2) with a concomitant decline in FAS [64] and in K8 [65] (discussed below), especially in the liver of aged rats.

RNH1 belongs to the leucine-rich repeats (LRR) motif protein superfamily [66] and is a tight-binding cytosolic inhibitor of the RNase A family with both ribonucleolytic and angiogenic activities that are essential for cell survival [67]. In addition, $\mathrm{RNH} 1$ is a known regulator of vascularization and a mediator of oxidative stress. Knockdown of RNH1 has been shown to significantly decrease cell survival under stress conditions, accompanied with an increase in cell apoptosis. The reported antioxidant [68] and redox homeostatic [69] effects might also contribute to the regulatory function of RNH1 in cell survival. These results suggest that overexpression of RNH1 has antioxidant effects that protect against hepatic damage and apoptosis induced by $\mathrm{H}_{2} \mathrm{O}_{2}$ in mice [68]. In this context, it should be noted that RNH1 was observed to be upregulated by exercise in the current study, which is likely related to the increase in antioxidant activity and antiapoptosis effects as suggested by the increase in MnSOD activity and the levels of hepatic GSH (Figure 2).

Tight regulation of proteostasis is essential for maintaining cellular homeostasis in postmitotic tissues [70]. Advanced age is an intrinsic process that results in alterations of tissue protein homoeostasis. These degenerative changes are intimately associated with abnormal protein aggregation and impaired protein degradation pathways. Direct interventions to modulate protein quality control mechanisms might therefore improve health and potentially increase lifespan. Proteasomes can be regarded as the major proteolytic enzymes responsible for the degradation of the majority of cellular proteins [71]. PSMB6 is a member of the 20S proteasomal subunit family, which forms the proteolytic core of the $26 \mathrm{~S}$ proteasome [71]. Beta subunits are characterized as containing the active sites of proteases, whereas the subunits serve as docking domains for the regulatory particles and form a gate that blocks unregulated access of substrates to the central pore. The age-associated decrease in the activity of the $26 \mathrm{~S}$ proteasomes, which are responsible for the degradation of ubiquitinated proteins, is in accordance with previous findings that high-molecular-weight ubiquitinprotein conjugates accumulate in various tissues over time [70].

In this context, it is interesting to note that, in addition to the increase in the activity of antioxidant enzymes known to occur in the liver of aged rats as a result of training exercise, the upregulation of proteasomes might also play a significant role in improved metabolism by reducing the amount of damaged proteins in the liver. Radák et al. [72] previously showed that regular moderate exercise initiated at advanced age and continued for two months in BDF1 mice resulted in significant upregulation of the activity of antioxidant enzymes and $26 \mathrm{~S}$ proteasomes in the brain. Our findings are also in accordance with previous reports that exercise training mitigated to a substantial degree of oxidative stress caused by advanced age, with a concomitant increase in proteasomal peptidase activities in the brain.

$\mathrm{K} 8$, a cytoprotective stress protein, belongs to the keratin family of cytoskeletal intermediate filament proteins that play a central role in protecting hepatocytes from apoptosis; accordingly, K8 mutations predispose their carriers to liver cirrhosis [73]. Emerging evidence also indicates that K8 protects cells from nonmechanical injury by cellular survival kinases and cell cycle progression [74]. Subsequent studies 
have suggested that keratins modulate apoptosis induced by FAS [73] and tumor necrosis factor [75]. In cirrhotic livers, K8 hyperphosphorylation was previously shown to occur preferentially in hepatic nodule cells adjacent to bridging fibrosis and was associated with increased stress kinase activation, oxidative injury, and susceptibility to undergo apoptosis [65]. Furthermore, according to Kucukoglu et al. [76], a high-fat diet triggers aggregate formation and the development of liver oxidative injury in susceptible individuals through the misfolding and cross-linking of excess K8. The possibility that the improvement in liver fibrosis and fatty liver mediated by exercise is associated with modulation of K8 in the livers of aged rats requires further study.

$\mathrm{HP}$ is produced as an acute-phase reactant during liver fibrosis (LF), and it possesses anti-inflammatory and antioxidative properties [77], preventing liver damage. Thus, HP might be a potential molecular target for early LF diagnostics and therapeutic applications [78]. In contrast, lack of HP attenuates the hepatomegaly/steatosis often associated with obesity. When animals were stressed by acute exercise or by a high-fat diet in a previous study, oxidative stress, muscle atrophy, and force drop were exacerbated in HP-knockout mice [79]. Conversely, recent data demonstrated that the increased HP levels in the serum in response to traumatic brain injury were derived from the liver and that IL-6 is an important mediator of this induction [80]. T-kininogen has also been demonstrated to be a cysteine proteinase inhibitor present in rat plasma [81]. In a previous report, preliminary evidence suggested that the degree of reduction in plasma T-kininogen levels was directly related to the severity of impaired liver function [81]. Recent results showed that aged rats present reduced expression of T-kininogen and HP and increased hepatic injury in response to an inflammatory insult [82]. Therefore, the upregulation of HP and T-kininogen following training exercise observed in this study might be the consequence of decreased levels of markers of inflammation and oxidative stress (Figure 2) in the livers of aged rats.

This study has several limitations. First, the changes in protein levels were not confirmed by western blot. Second, comprehensive data were not obtained regarding the phenotype of the aging liver, such as the presence of liver tissue histology, hepatocyte apoptosis, intrahepatic lipid accumulation, or cirrhosis. Third, we only measured levels of primary antioxidative enzymes (MnSOD and GSH), secondary antioxidative enzymes such as glutathione-Stransferase (GST) and glucose 6-phosphate dehydrogenase, and molecules such as glutathione.

In summary, we succeeded in objectively identifying 12 proteins that exhibited adaptive changes in their expression associated with extended exercise in the livers of aged rats. Identification and detailed analysis of the impacted proteins indicated that exercise training significantly altered the expression of several proteins involved in key liver metabolic pathways including sulfur, glycolysis, and methionine metabolism as well as general protein metabolism in conjunction with the modulation of overall hepatic protein expression profiles. These proteins are potential disease stateand intervention-specific biomarkers. Further research on these specific proteins is needed to uncover possible pathways involved in the beneficial effects of exercise on metabolic adaptations in the liver of aged rats.

\section{Competing Interests}

The authors declare that they have no competing interests.

\section{Acknowledgments}

The current project was supported by the National Natural Science Foundation of China (Grant 31500961) and the Guangdong Scientific Project (Grant 2014A020220015 and Grant 2015A020219015) and partially supported by the Distinguished Young Talents in Higher Education of Guangdong, China (Grant 2014KQNCX225).

\section{References}

[1] N. M. Johannsen, D. L. Swift, C. J. Lavie, C. P. Earnest, S. N. Blair, and T. S. Church, "Combined aerobic and resistance training effects on glucose homeostasis, fitness, and other major health indices: a review of current guidelines," Sports Medicine, vol. 46, no. 12, pp. 1809-1818, 2016.

[2] P.-S. Lin, C.-C. Hsieh, H.-S. Cheng, T.-J. Tseng, and S.-C. Su, "Association between physical fitness and successful aging in taiwanese older adults," PLoS ONE, vol. 11, no. 3, Article ID e0150389, 2016.

[3] Z. Radak, Z. Zhao, E. Koltai, H. Ohno, and M. Atalay, "Oxygen consumption and usage during physical exercise: the balance between oxidative stress and ROS-dependent adaptive signaling," Antioxidants and Redox Signaling, vol. 18, no. 10, pp. 12081246, 2013.

[4] K. J. A. Davies, A. T. Quintanilha, G. A. Brooks, and L. Packer, "Free radicals and tissue damage produced by exercise," Biochemical and Biophysical Research Communications, vol. 107, no. 4, pp. 1198-1205, 1982.

[5] L. L. Ji, "Exercise-induced modulation of antioxidant defense," Annals of the New York Academy of Sciences, vol. 959, pp. 82-92, 2002.

[6] W. Dröge, "Aging-related changes in the thiol/disulfide redox state: implications for the use of thiol antioxidants," Experimental Gerontology, vol. 37, no. 12, pp. 1333-1345, 2002.

[7] X. Hu, Z. Duan, H. Hu et al., "Proteomic profile of carbonylated proteins in rat liver: exercise attenuated oxidative stress may be involved in fatty liver improvement," Proteomics, vol. 13, no. 1011, pp. 1755-1764, 2013.

[8] L. L. Ji, C. Kang, and Y. Zhang, "Exercise-induced hormesis and skeletal muscle health," Free Radical Biology and Medicine, vol. 98, pp. 113-122, 2016.

[9] P. Wiklund, X. Zhang, S. Pekkala et al., "Insulin resistance is associated with altered amino acid metabolism and adipose tissue dysfunction in normoglycemic women," Scientific Reports, vol. 6, Article ID 24540, 11 pages, 2016.

[10] N. Houstis, E. D. Rosen, and E. S. Lander, "Reactive oxygen species have a causal role in multiple forms of insulin resistance," Nature, vol. 440, no. 7086, pp. 944-948, 2006.

[11] S. Goto, Z. Radák, C. Nyakas et al., "Regular exercise: an effective means to reduce oxidative stress in old rats," Annals of the New York Academy of Sciences, vol. 1019, pp. 471-474, 2004. 
[12] Z. Radak, H. Y. Chung, H. Naito et al., "Age-associated increase in oxidative stress and nuclear factor kappaB activation are attenuated in rat liver by regular exercise," The FASEB Journal, vol. 18, no. 6, pp. 749-750, 2004.

[13] R. J. F. Loos, J. M. Hagberg, L. Pérusse et al., "Advances in exercise, fitness, and performance genomics in 2014," Medicine \& Science in Sports and Exercise, vol. 47, no. 6, pp. 1105-1112, 2015.

[14] H. Yuan, Y. Niu, X. Liu et al., "Proteomic analysis of skeletal muscle in insulin-resistant mice: response to 6-week aerobic exercise," PLoS ONE, vol. 8, no. 1, Article ID e53887, 2013.

[15] R. Liu, J. W. Kenney, A. Manousopoulou et al., "Quantitative non-canonical amino acid tagging (QuaNCAT) proteomics identifies distinct patterns of protein synthesis rapidly induced by hypertrophic agents in cardiomyocytes, revealing new aspects of metabolic remodeling," Molecular \& Cellular Proteomics, vol. 15, no. 10, pp. 3170-3189, 2016.

[16] M. K. Nøhr, T. P. Kroager, K. W. Sanggaard et al., "SILAC-MS based characterization of lps and resveratrol induced changes in adipocyte proteomics - resveratrol as ameliorating factor on LPS induced changes," PLoS ONE, vol. 11, no. 7, Article ID e0159747, 2016.

[17] G. Gat-Yablonski, A. Finka, G. Pinto, M. Quadroni, B. Shtaif, and P. Goloubinoff, "Quantitative proteomics of rat livers shows that unrestricted feeding is stressful for proteostasis with implications on life span," Aging, vol. 8, no. 8, pp. 1735-1758, 2016.

[18] S. Yoon, J. Lee, and S.-M. Lee, "Combined treatment of isoflavone supplementation and exercise restores the changes in hepatic protein expression in ovariectomized rats-a proteomics approach," Journal of the International Society of Sports Nutrition, vol. 11, no. 29, pp. 1-8, 2014.

[19] J. R. Zierath and H. Wallberg-Henriksson, "Looking ahead perspective: where will the future of exercise biology take us?" Cell Metabolism, vol. 22, no. 1, pp. 25-30, 2015.

[20] F. Li, H. Yu, L. Xiao, and Y. Liu, "Response of BAX, Bcl-2 proteins, and SIRT1/PGC- $1 \alpha$ mRNA expression to 8-week treadmill running in the aging rat skeletal muscle," in Oxygen Transport to Tissue XXXVIII, vol. 923 of Advances in Experimental Medicine and Biology, pp. 283-289, Springer, 2016.

[21] W. Song, H.-B. Kwak, and J. M. Lawler, "Exercise training attenuates age-induced changes in apoptotic signaling in rat skeletal muscle," Antioxidants \& Redox Signaling, vol. 8, no. 3-4, pp. 517-528, 2006.

[22] P. M. Siu, R. W. Bryner, J. K. Marty, and S. E. Alway, "Apoptotic adaptations from exercise training in skeletal and cardiac muscles," FASEB Journal, vol. 18, no. 10, pp. 1150-1152, 2004.

[23] J. Bejma, R. Ramires, and L. L. Ji, "Free radical generation and oxidative stress with ageing and exercise: differential effects in the myocardium and liver," Acta Physiologica Scandinavica, vol. 169 , no. 4, pp. 343-351, 2000.

[24] B. Sun, J. H. Wang, Y. Y. Lv, S. S. Zhu, J. Yang, and J. Z. Ma, "Proteomic adaptation to chronic high intensity swimming training in the rat heart," Comparative Biochemistry and Physiology Part D: Genomics and Proteomics, vol. 3, no. 1, pp. 108-117, 2008.

[25] D. N. Perkins, D. J. C. Pappin, D. M. Creasy, and J. S. Cottrell, "Probability-based protein identification by searching sequence databases using mass spectrometry data," Electrophoresis, vol. 20, no. 18, pp. 3551-3567, 1999.

[26] A. Kuhla, T. Blei, R. Jaster, and B. Vollmar, "Aging is associated with a shift of fatty metabolism toward lipogenesis," Journals of
Gerontology - Series A Biological Sciences and Medical Sciences, vol. 66, no. 11, pp. 1192-1200, 2011.

[27] L. A. Finlay, A. J. Michels, J. A. Butler et al., "R- $\alpha$-lipoic acid does not reverse hepatic inflammation of aging, but lowers lipid anabolism, while accentuating circadian rhythm transcript profiles," American Journal of Physiology-Regulatory Integrative and Comparative Physiology, vol. 302, no. 5, pp. R587-R597, 2012.

[28] J. P. Garee and S. Oesterreich, "SAFB1's multiple functions in biological control-lots still to be done!," Journal of Cellular Biochemistry, vol. 109, no. 2, pp. 312-319, 2010.

[29] S. Oesterreich, Q. P. Zhang, and A. V. Lee, "Inhibition of oestrogen receptor activity by the co-repressor HET/SAF-B is relieved by blockade of histone deacetylase activity," The European Journal of Cancer, vol. 36, supplement 4, pp. S43-S44, 2000.

[30] F. Weighardt, F. Cobianchi, L. Cartegni et al., "A novel hnRNP protein (HAP/SAF-B) enters a subset of hnRNP complexes and relocates in nuclear granules in response to heat shock," Journal of Cell Science, vol. 112, no. 10, pp. 1465-1476, 1999.

[31] P. Peidis, N. Voukkalis, E. Aggelidou et al., "SAFB1 interacts with and suppresses the transcriptional activity of p53," FEBS Letters, vol. 585, no. 1, pp. 78-84, 2011.

[32] J. Lin, P. Xu, P. LaVallee, and J. R. Hoidal, "Identification of proteins binding to E-Box/Ku86 sites and function of the tumor suppressor SAFB1 in transcriptional regulation of the human xanthine oxidoreductase gene," Journal of Biological Chemistry, vol. 283, no. 44, pp. 29681-29689, 2008.

[33] M.-B. Debril, L. Dubuquoy, J.-N. Feige et al., "Scaffold attachment factor B1 directly interacts with nuclear receptors in living cells and represses transcriptional activity," Journal of Molecular Endocrinology, vol. 35, no. 3, pp. 503-517, 2005.

[34] Y. Omura, Y. Nishio, T. Takemoto et al., "SAFB1, an RBMXbinding protein, is a newly identified regulator of hepatic SREBP-1c gene," BMB Reports, vol. 42, no. 4, pp. 232-237, 2009.

[35] Y.-B. Lee, S. Colley, M. Norman, G. Biamonti, and J. B. Uney, "SAFB re-distribution marks steps of the apoptotic process," Experimental Cell Research, vol. 313, no. 18, pp. 3914-3923, 2007.

[36] H. Kondoh, M. E. Lleonart, D. Bernard, and J. Gil, "Protection from oxidative stress by enhanced glycolysis; a possible mechanism of cellular immortalization," Histology and Histopathology, vol. 22, no. 1, pp. 85-90, 2007.

[37] T. J. Rothwell and M. D. Sayce, "The stability of PGM and AK isoenzymes in human tissues," Journal of Forensic Sciences, vol. 19, no. 3, pp. 590-598, 1974.

[38] T. Stojkovic, J. Vissing, F. Petit et al., "Muscle glycogenosis due to phosphoglucomutase 1 deficiency," New England Journal of Medicine, vol. 361, no. 4, pp. 425-427, 2009.

[39] M. Gueugneau, C. Coudy-Gandilhon, O. Gourbeyre et al., "Proteomics of muscle chronological ageing in post-menopausal women," BMC Genomics, vol. 15, article 1165, 24 pages, 2014.

[40] T. Nishikawa, N. Bellance, A. Damm et al., "A switch in the source of ATP production and a loss in capacity to perform glycolysis are hallmarks of hepatocyte failure in advance liver disease," Journal of Hepatology, vol. 60, no. 6, pp. 1203-1211, 2014.

[41] N. Preisler, P. Laforêt, A. Echaniz-Laguna et al., "Fat and carbohydrate metabolism during exercise in phosphoglucomutase type 1 deficiency," The Journal of Clinical Endocrinology and Metabolism, vol. 98, no. 7, pp. E1235-E1240, 2013.

[42] V. A. Spitsyn, A. K. Nafikova, N. K. Spitsynaet et al., "Genetic predisposition to development of toxic liver cirrhosis caused by alcohol," Genetika, vol. 37, no. 5, pp. 698-707, 2001. 
[43] M. Nishinari, N. Aoyama, Z. Ogawa et al., "Phosphoglucomutase activity as a novel biomarker in patients with acute myocardial infarction," Circulation Journal, vol. 76, no. 9, pp. 2197-2203, 2012.

[44] F. Gloria-Bottini, A. Magrini, E. Antonacci et al., "Phosphoglucomutase genetic polymorphism and body mass," American Journal of the Medical Sciences, vol. 334, no. 6, pp. 421-425, 2007.

[45] S. Krähenbühl, S. Krähenbühl-Glauser, J. Stucki, P. Gehr, and J. Reichen, "Stereological and functional analysis of liver mitochondria from rats with secondary biliary cirrhosis: impaired mitochondrial metabolism and increased mitochondrial content per hepatocyte," Hepatology, vol. 15, no. 6, pp. 1167-1172, 1992.

[46] M. Capello, S. Ferri-Borgogno, P. Cappello, and F. Novelli, " $\alpha$ Enolase: a promising therapeutic and diagnostic tumor target," The FEBS Journal, vol. 278, no. 7, pp. 1064-1074, 2011.

[47] V. Pancholi, "Multifunctional $\alpha$-enolase: its role in diseases," Cellular and Molecular Life Sciences, vol. 58, no. 7, pp. 902-920, 2001.

[48] B. Peng, X. Huang, E. S. Nakayasu et al., "Using immunoproteomics to identify alpha-enolase as an autoantigen in liver fibrosis," Journal of Proteome Research, vol. 12, no. 4, pp. 17891796, 2013.

[49] J. Kluwe, J.-P. Pradere, G.-Y. Gwak et al., "Modulation of hepatic fibrosis by c-Jun-N-terminal kinase inhibition," Gastroenterology, vol. 138, no. 1, pp. 347-359, 2010.

[50] G. Poli, "Pathogenesis of liver fibrosis: role of oxidative stress," Molecular Aspects of Medicine, vol. 21, no. 3, pp. 49-98, 2000.

[51] D. E. W. Livingstone and B. R. Walker, "Is $11 \beta$-hydroxysteroid dehydrogenase type 1 a therapeutic target? Effects of carbenoxolone in lean and obese Zucker rats," Journal of Pharmacology and Experimental Therapeutics, vol. 305, no. 1, pp. 167-172, 2003.

[52] T. Honma, N. Shinohara, J. Ito et al., "High-fat diet intake accelerates aging, increases expression of Hsd1lb1, and promotes lipid accumulation in liver of SAMP10 mouse," Biogerontology, vol. 13, no. 2, pp. 93-103, 2012.

[53] J. M. Paterson, N. M. Morton, C. Fievet et al., "Metabolic syndrome without obesity: hepatic overexpression of $11 \beta$ hydroxysteroid dehydrogenase type 1 in transgenic mice," Proceedings of the National Academy of Sciences of the United States of America, vol. 101, no. 18, pp. 7088-7093, 2004.

[54] J. E. Campbell, M. A. Király, D. J. Atkinson, A. M. D’Souza, M. Vranic, and M. C. Riddell, "Regular exercise prevents the development of hyperglucocorticoidemia via adaptations in the brain and adrenal glands in male Zucker diabetic fatty rats," American Journal of Physiology-Regulatory Integrative and Comparative Physiology, vol. 299, no. 1, pp. R168-R176, 2010.

[55] R. M. Barrientos, V. M. Thompson, M. M. Kitt et al., "Greater glucocorticoid receptor activation in hippocampus of aged rats sensitizes microglia," Neurobiology of Aging, vol. 36, no. 3, pp. 1483-1495, 2015.

[56] S. Mani, W. Cao, L. Wu, and R. Wang, "Hydrogen sulfide and the liver," Nitric Oxide, vol. 41, pp. 62-71, 2014.

[57] V. Tiranti, C. Viscomi, T. Hildebrandt et al., "Loss of ETHE1, a mitochondrial dioxygenase, causes fatal sulfide toxicity in ethylmalonic encephalopathy," Nature Medicine, vol. 15, no. 2, pp. 200-205, 2009.

[58] D. Mancardi, C. Penna, A. Merlino, P. Del Soldato, D. A. Wink, and P. Pagliaro, "Physiological and pharmacological features of the novel gasotransmitter: hydrogen sulfide," Biochimica et Biophysica Acta-Bioenergetics, vol. 1787, no. 7, pp. 864-872, 2009.
[59] B. L. Predmore, M. J. Alendy, K. I. Ahmed, C. Leeuwenburgh, and D. Julian, "The hydrogen sulfide signaling system: changes during aging and the benefits of caloric restriction," Age, vol. 32, no. 4, pp. 467-481, 2010.

[60] I. Baiges, J. Palmfeldt, C. Bladé, N. Gregersen, and L. Arola, "Lipogenesis is decreased by grape seed proanthocyanidins according to liver proteomics of rats fed a high fat diet," Molecular \& Cellular Proteomics, vol. 9, no. 7, pp. 1499-1513, 2010.

[61] H. Higashitsuji, H. Higashitsuji, T. Nagao et al., "A novel protein overexpressed in hepatoma accelerates export of NF- $\kappa \mathrm{B}$ from the nucleus and inhibits p53-dependent apoptosis," Cancer Cell, vol. 2, no. 4, pp. 335-346, 2002.

[62] C. Cabrero, A. M. Duce, P. Ortiz, S. Alemany, and J. M. Mato, "Specific loss of the high-molecular-weight form of S-adenosylL-methionine synthetase in human liver cirrhosis," Hepatology, vol. 8, no. 6, pp. 1530-1534, 1988.

[63] J. M. Mato, F. J. Corrales, S. C. Lu, and M. A. Avila, "Sadenosylmethionine: a control switch that regulates liver function," The FASEB Journal, vol. 16, no. 1, pp. 15-26, 2002.

[64] C. Dahlhoff, S. Worsch, M. Sailer et al., "Methyl-donor supplementation in obese mice prevents the progression of NAFLD, activates AMPK and decreases acyl-carnitine levels," Molecular Metabolism, vol. 3, no. 5, pp. 565-580, 2014.

[65] Q. Zhou, X. Ji, L. Chen, H. B. Greenberg, S. C. Lu, and M. B. Omary, "Keratin mutation primes mouse liver to oxidative injury," Hepatology, vol. 41, no. 3, pp. 517-525, 2005.

[66] D. Nadano, T. Yasuda, H. Takeshita, K. Uchide, and K. Kishi, "Purification and characterization of human brain ribonuclease inhibitor," Archives of Biochemistry and Biophysics, vol. 312, no. 2, pp. 421-428, 1994.

[67] E. Pizzo, C. Sarcinelli, J. Sheng et al., "Ribonuclease/angiogenin inhibitor 1 regulates stress-induced subcellular localization of angiogenin to control growth and survival," Journal of Cell Science, vol. 126, no. 18, pp. 4308-4319, 2013.

[68] X. Y. Cui, P. F. Fu, D. N. Pan, Y. Zhao, J. Zhao, and B. C. Zhao, "The antioxidant effects of ribonuclease inhibitor," Free Radical Research, vol. 37, no. 10, pp. 1079-1085, 2003.

[69] D. M. Monti, N. Montesano Gesualdi, J. Matoušek, F. Esposito, and G. D'Alessio, "The cytosolic ribonuclease inhibitor contributes to intracellular redox homeostasis," FEBS Letters, vol. 581, no. 5, pp. 930-934, 2007.

[70] S. Goto, R. Takahashi, A. Kumiyama et al., "Implications of protein degradation in aging," Annals of the New York Academy of Sciences, vol. 928, pp. 54-64, 2001.

[71] Z. Radák, R. Takahashi, A. Kumiyama et al., "Effect of aging and late onset dietary restriction on antioxidant enzymes and proteasome activities, and protein carbonylation of rat skeletal muscle and tendon," Experimental gerontology, vol. 37, no. 12, pp. 1423-1430, 2002.

[72] Z. Radák, T. Kaneko, S. Tahara et al., "Regular exercise improves cognitive function and decreases oxidative damage in rat brain," Neurochemistry International, vol. 38, no. 1, pp. 17-23, 2001.

[73] N.-O. Ku, R. M. Soetikno, and M. B. Omary, "Keratin mutation in transgenic mice predisposes to Fas but not TNF-induced apoptosis and massive liver injury," Hepatology, vol. 37, no. 5, pp. 1006-1014, 2003.

[74] J. D. Rotty, G. W. Hart, and P. A. Coulombe, "Stressing the role of O-GlcNAc: linking cell survival to keratin modification," Nature Cell Biology, vol. 12, no. 9, pp. 847-849, 2010. 
[75] C. Caulin, C. F. Ware, T. M. Magin, and R. G. Oshima, "Keratin-dependent, epithelial resistance to tumor necrosis factor-induced apoptosis," The Journal of Cell Biology, vol. 149, no. 1, pp. 17-22, 2000.

[76] O. Kucukoglu, N. Guldiken, Y. Chen et al., "High-fat diet triggers Mallory-Denk body formation through misfolding and crosslinking of excess keratin 8," Hepatology, vol. 60, no. 1, pp. 169-178, 2014.

[77] A. Jelena, M. Mirjana, B. Desanka et al., "Haptoglobin and the inflammatory and oxidative status in experimental diabetic rats: antioxidant role of haptoglobin," Journal of Physiology and Biochemistry, vol. 69, no. 1, pp. 45-58, 2013.

[78] A. Zhang, H. Sun, W. Sun, Y. Ye, and X. Wang, "Proteomic identification network analysis of haptoglobin as a key regulator associated with liver fibrosis," Applied Biochemistry and Biotechnology, vol. 169, no. 3, pp. 832-846, 2013.

[79] E. Bertaggia, G. Scabia, S. Dalise et al., "Haptoglobin is required to prevent oxidative stress and muscle atrophy," PLoS ONE, vol. 9, no. 6, Article ID e100745, 2014.

[80] S. Yang, Y. Ma, Y. Liu, H. Que, C. Zhu, and S. Liu, "Elevated serum haptoglobin after traumatic brain injury is synthesized mainly in liver," Journal of Neuroscience Research, vol. 91, no. 2, pp. 230-239, 2013.

[81] C. Henkel, K. Schwamborn, H. W. Zimmermann et al., "From proteomic multimarker profiling to interesting proteins: Thymosin- $\beta_{4}$ and kininogen-1 as new potential biomarkers for inflammatory hepatic lesions," Journal of Cellular and Molecular Medicine, vol. 15, no. 10, pp. 2176-2188, 2011.

[82] C. R. Gomez, C. Acuña-Castillo, C. Pérez et al., "Diminished acute phase response and increased hepatic inflammation of aged rats in response to intraperitoneal injection of lipopolysaccharide," The Journals of Gerontology Series A: Biological Sciences and Medical Sciences, vol. 63, no. 12, pp. 1299-1306, 2008. 


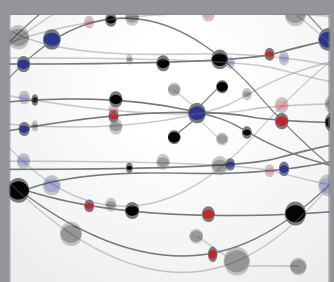

The Scientific World Journal
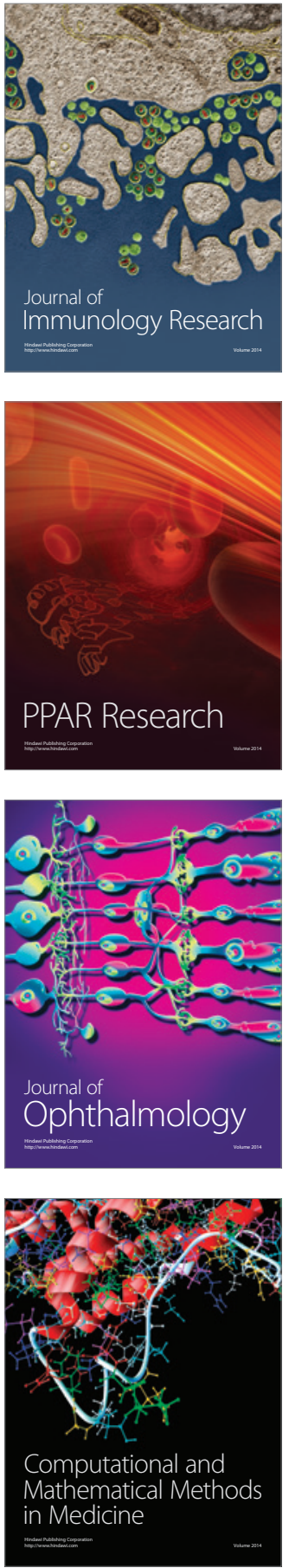

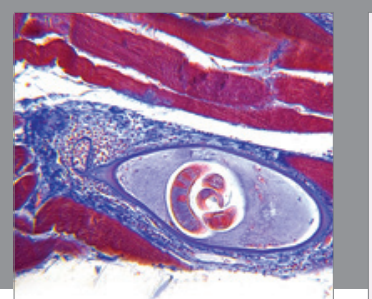

Gastroenterology Research and Practice

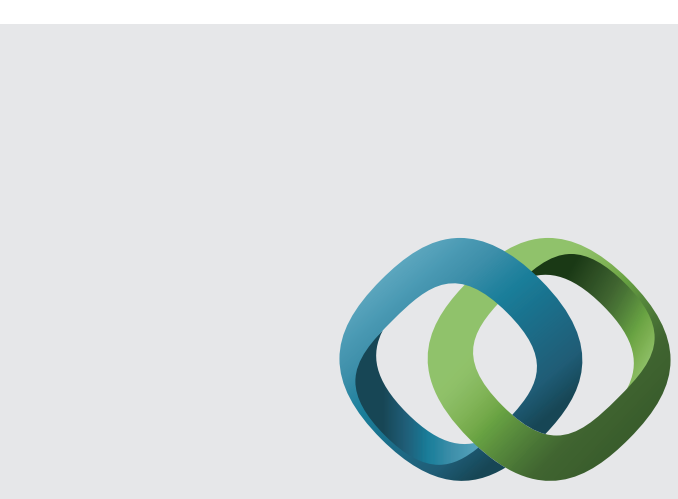

\section{Hindawi}

Submit your manuscripts at

http://www.hindawi.com
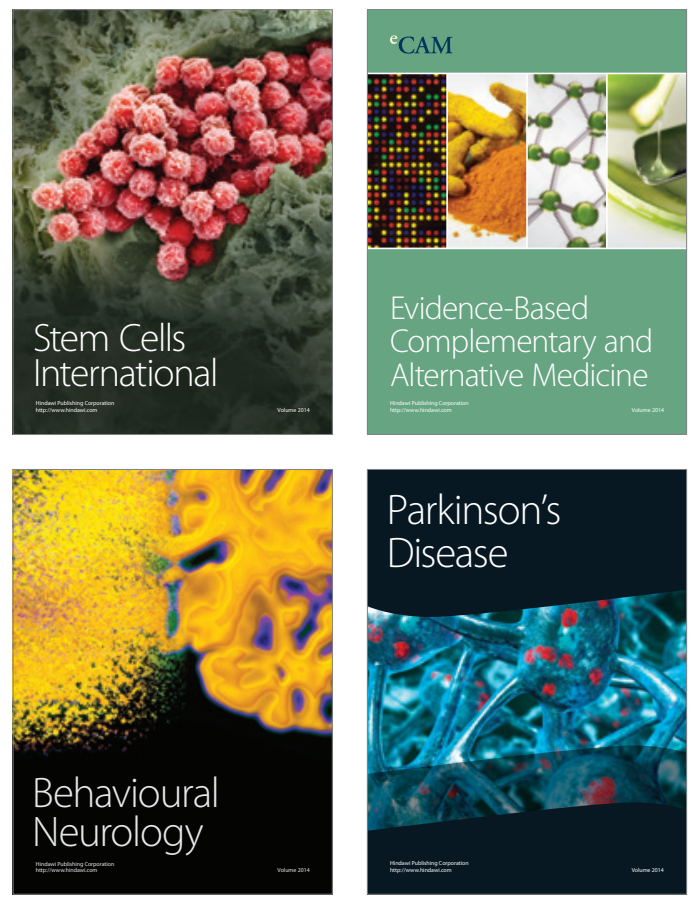
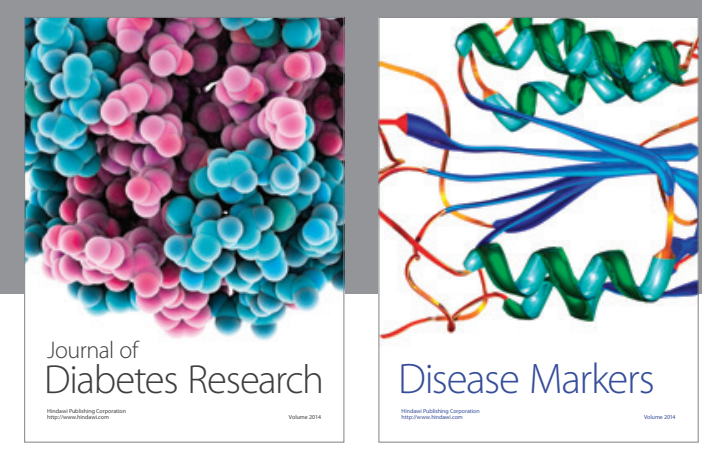

Disease Markers
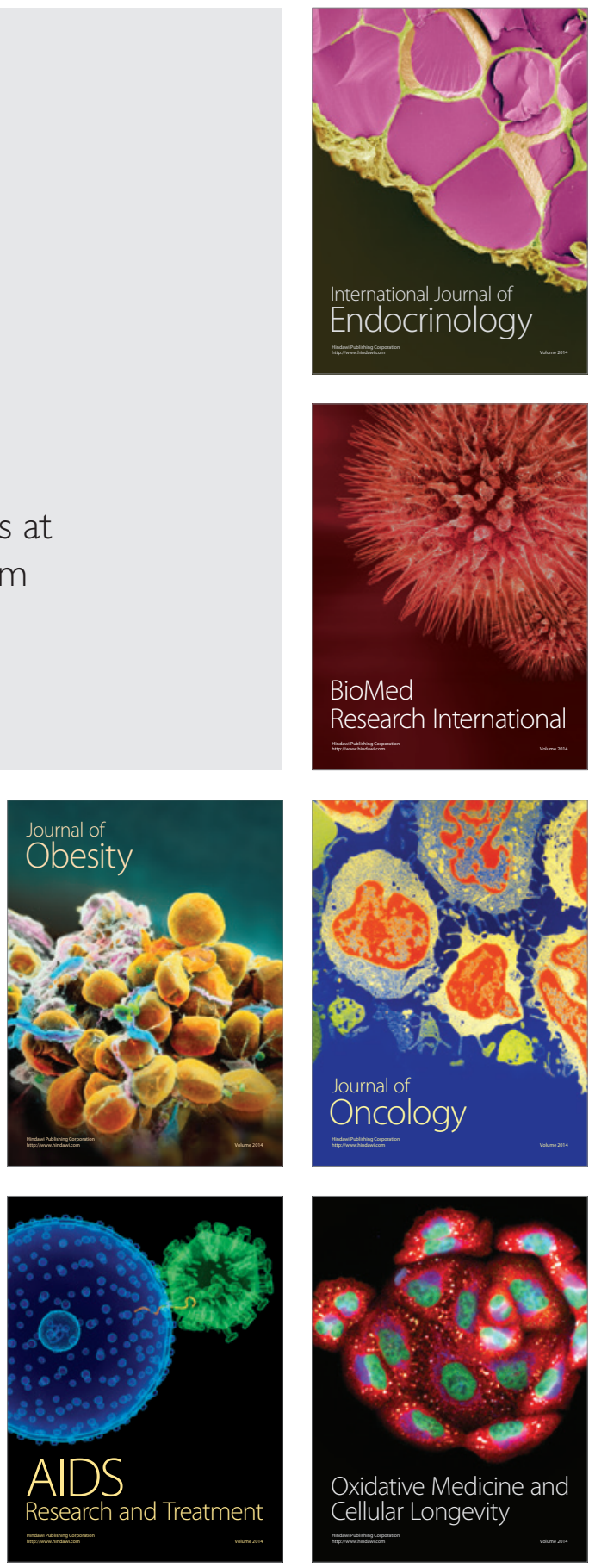